\title{
Assessment of PBTs in the European Union: a critical assessment of the proposed evaluation scheme with reference to plant protection products
}

\author{
Keith Solomon ${ }^{1 *}$, Michael Matthies ${ }^{2}$ and Marco Vighi ${ }^{3}$
}

\begin{abstract}
A number of international and national programs classify substances that are persistent ( $P$ or very $P)$, bioaccumulative (B or very $B$ ), toxic $(T)$, or have the potential for long-range transport. The oldest of these programs is the Stockholm Convention on Persistent Organic Pollutants. More recent programs address persistent, bioaccumulative, and toxic (PBT) properties for chemicals in general (Registration, Evaluation, Authorisation and Restriction of Chemicals, REACH; EC 253/2011) and plant protection products (PPPs) (EC 1107/2009). However, these programs used different criteria for categorization. We critically assessed the criteria and process used in the categorization of PPPs and noted that EC1107/2009, in contrast to the Stockholm Convention or REACH, offers no process for carrying out a further, more refined assessment of those pesticides that are identified as having PBT properties. Thus, in contrast to REACH, few basic screening criteria are used for final-step management decisions. Guidance on the selection of data is not provided, and the criteria used are unclear. For example, no guidance is given as to how the half-lives in soil, water, and sediment should be derived and the term 'half-life' is not clearly defined. Large amounts of useful data on environmental and toxicological properties are available for PPPs but most of this is not used in the categorization, for example, photolysis in water, water-sediment, and on soil, important environmental degradation processes particularly relevant to pesticides. The criteria for bioaccumulation and toxicity appear to be focused only on aquatic ecosystems and do not address the terrestrial compartment which is particularly relevant for pesticides and potentially relevant for PBT considerations. The categorization process under EC 1107/2009 could be made more efficient and reduce false negatives and positives if a formal weight of evidence approach was applied to multiple lines of evidence. This paper presents these ideas and how they can be incorporated into the framework for categorization to better classify plant protection products in terms of persistence, bioaccumulation, and toxicity.
\end{abstract}

Keywords: EC 1107/2009, PBT, POP, Pesticide, PPP

\section{Background}

There are a number of international and national programs that are concerned with the categorization of substances that are persistent $(\mathrm{P}$ or very $\mathrm{P}(\mathrm{v} P))$, bioaccumulative (B or very $B(v B)$ ), toxic $(T)$, or have the potential for long-range transport (LRT) [1]. The

\footnotetext{
* Correspondence: ksolomon@uoguelph.ca

${ }^{1}$ Centre for Toxicology, School of Environmental Sciences, University of Guelph, 2120 EC Bovey Building, Gordon Street, Guelph, Ontario N1G 2W1, Canada

Full list of author information is available at the end of the article
}

objectives of these programs are protection of the environment and humans from substances that may harm these entities, either locally or globally, by accumulation in organisms where they then exert toxic effects. The oldest of these programs is the Stockholm Convention on Persistent Organic Pollutants (POPs) and is coordinated by the United Nations Environment Programme [2]. Related to this convention is the recognition of the potential for long-range transboundary air pollution as another issue of relevance to POPs [3]. The objectives of the Stockholm convention on POPs have been 
incorporated into several other jurisdictions such as the Persistent Organic Pollutant (POP) Regulations in the European Union (EU) [4].

In addition to the multinational conventions, there are a number of other programs in Europe that consider persistent, bioaccumulative, and toxic (PBT) properties of chemicals. These criteria for PBTs are different from those used to classify POPs as they employ shorter halflives, smaller bioconcentration factors, and do not consider long-range transport in the same way as for POPs. The Programs in the EU recently have been reviewed by Moermond et al. [1] who pointed out that there are significant inconsistencies in the criteria used for categorization of PBTs and that these inconsistencies extend to the procedures for management of risks from the PBTs. They also point out that these differences create a challenge to the harmonization of the assessment of substances that have the properties of PBTs and/or vPvBs. Some of categorization schemes, such as that used in Registration, Evaluation, Authorization and Restriction of Chemicals (REACH) [5], make use of criteria that are followed by a weight-of-evidence analysis; while others, such as those for categorization of plant protection products (PPPs), base management decisions on basic PBT criteria only.

The criteria for the categorization of the POPs were developed in the late 1990s by the Criteria Expert Group for Persistent Organic Pollutants [6]. These criteria were developed by scientific consensus (A Gilman, personal communication) but are very similar to the criteria for P and B that were proposed in Canada in 1995
[7] and later incorporated in the management policy for toxic substances in Canada [8]. The criteria were based on the properties of a number of compounds [9], all of which were subsequently classified as POPs under the Stockholm Convention. It is important to note that neither of these Canadian documents nor the POP Convention [2] recommended the use of the criteria for $P, B$, and $\mathrm{T}$ as a final step in the process of risk management but rather that decisions be made 'after rigorous scientific assessment' [8] and that 'Expert opinion and a weight-of-evidence approach must play important roles in the interpretation of scientific data and in the application of the criteria presented here. This is particularly the case where persistence and bioaccumulation data identified for a substance are close to the critical values recommended' [7].

While we recognize the importance of the above challenges to the harmonization of categorization in global and local jurisdictions, the primary focus of this paper is on the criteria and process used for the categorization of PPPs under EU Regulation 1107/2009 [10]. To serve as the basis for discussions in the rest of the paper, the criteria for categorization are summarized in Table 1. Although our primary focus is on the PBT and not vPvB materials, some of the issues discussed are relevant to $\mathrm{vPvB}$ materials. Also, although categorization of substances susceptible to LRT is also considered in the regulations, this will not be specifically addressed.

The categorization of PPPs (which includes the technical active ingredient and any synergists and/or safeners, but not other formulants [10]) is based in the regulations of

Table 1 Summary of criteria for the categorization of plant protection products as PBT or vPvBT from [10]

\begin{tabular}{|c|c|c|}
\hline Criteria & POP & PBT \\
\hline \multicolumn{3}{|l|}{ Persistence $(P)$} \\
\hline \multirow[t]{4}{*}{ Persistent } & Water, DT50 > 2 months & Marine water, $t^{1} 12>60$ days \\
\hline & Sediment, DT50 > 6 months & Fresh water, $t 1 \frac{2}{2}>40$ days \\
\hline & Soil, DT50 > 6 months & Marine sediment, $t^{1} / 2>180$ days \\
\hline & & Soil, $t 11 / 2>120$ days \\
\hline \multirow[t]{3}{*}{ Very persistent } & - & Water, $t 1 / 2>60$ days \\
\hline & & Sediment, $t^{1} / 2>180$ days \\
\hline & & Soil, $t 11 / 2>180$ days \\
\hline \multicolumn{3}{|l|}{ Bioaccumulation (B) } \\
\hline \multirow[t]{2}{*}{ Bioaccumulative } & $\mathrm{BCF}>5,000$ or $\log K_{\mathrm{ow}}>5$ & $\mathrm{BCF}>2,000$ in aquatic species \\
\hline & $\begin{array}{l}\text { Other, e.g., very toxic or bioaccumulation in } \\
\text { nontarget species }\end{array}$ & \\
\hline Very bioaccumulative & - & $\mathrm{BCF}>5,000$ \\
\hline Toxicity (T) & $\begin{array}{l}\text { No specific criteria other than "significant adverse } \\
\text { effects" }\end{array}$ & $\begin{array}{l}\text { Chronic NOEC }<0.01 \mathrm{mg} / \mathrm{L} \text { or is a carcinogen, mutagen, or toxic for } \\
\text { reproduction, or other evidence of toxicity }\end{array}$ \\
\hline $\begin{array}{l}\text { Potential for long-range } \\
\text { transport (LRT) }\end{array}$ & $\begin{array}{l}\text { Air, DT50 > } 2 \text { d or modeling or monitoring data } \\
\text { which shows long-range transport }\end{array}$ & None \\
\hline
\end{tabular}

$t^{1} / 2$, half-life. 
the EU and this is recognized. The objective of this critical review is to consider the science used in this process and to offer suggestions for methods for the selection of the most appropriate data for conducting the categorization. By appropriately selecting the relevant data to be used in the cut-off process, false positives can be reduced while still identifying the critical compounds with greater certainty. Our focus here is on EC $1107 / 2009$, but some of the points we raise may be useful in the context of other regulations.

\section{Main text Methods}

As the nature of this paper is a discussion paper, we searched the literature for papers, reports, and government documents relevant to the topic of persistence, bioaccumulation, and toxicity of chemicals. The literature was searched using databases such as SciFinder and PubMed as well as citations in review articles. The focus of our search was on PPPs but, where relevant, data for other substances were used to inform our analysis. The report and papers resulting from the Society of Environmental Toxicology and Chemistry (SETAC) POPs workshop held in 2008 [11], et seq., were particularly useful in this regard.

\section{Protection goals}

As with any risk assessment concerned with the environment, the protection goals are important initial considerations. Protection goals provide a focus to the regulations and any hazard and/or risk assessments carried out under the regulation. Without protection goals, 'the statement of what is to be protected and the assessment endpoints to use as operational measure of the protection goal' [12], it is not possible to assess hazards or risks in a transparent manner. Individual organisms are rarely important in protection of ecological receptors [13]. Indeed, individuals can be removed from populations without necessarily affecting the size and dynamics of populations and of the structure and functions of biological communities and ecosystems that are the objective of ecological protection [14]. Therefore, a key issue in ecological risk assessment is extrapolation from data obtained on a few individuals in a few species to the effects on populations and to their consequences for ecosystem structure, processes, and services.

In some regulatory instruments for environment protection, such as REACH [15], EC 1107 [10], and Biocides Directives [16], the focus is on chemicals and the protection goals are only vaguely defined in biological terms. In other regulatory tools, such as the Water Framework Directive (WFD) [17], the Marine Strategy Framework Directive [18], and the forthcoming Soil Directive, the approach is more holistic, considering many potential stressors capable of affecting ecosystems and the assessment endpoints. Moreover, the focus of the regulations is on ecosystems and not on chemical substances. Finally, these regulatory instruments require a site-specific or region-specific assessment, accounting for the vulnerability and the particular ecological values of the ecosystems [19].

According to the WFD, the objective is the attainment of a 'good' ecological status defined as follows [17]:

The values of the biological quality elements for the surface water body type show low levels of distortion resulting from human activity, but deviate only slightly from those normally associated with the surface water-body type under undisturbed conditions.

This means that the goal for protection is to maintain the conditions of aquatic ecosystems as close as possible to the characteristics of natural water bodies not subject to human activities. This is an ambitious goal for aquatic ecosystems, but it is not applicable, in most cases, to the terrestrial environments where structure and functions of ecosystems have been greatly modified by human activities to provide specific services to humans such as food, housing, infrastructure, and recreation. Typical cases are agricultural areas where an artificial ecosystem (the agro-ecosystem) is established and is not intended be returned to natural conditions. In these cases, the goals for protection are different, consisting of a combination of ecological function and human needs and a more anthropocentric concept of environmental protection [20]. A reasonable goal for these kinds of ecosystems is the protection of 'ecosystem services', ensuring that the ecosystem services are maintained in a sustainable way while still allowing modifications and impacts on ecosystems in order to provide specific services to human needs such as agricultural production [21].

\section{Combinations of properties related to $\mathrm{P}, \mathrm{B}$, and $\mathrm{T}$}

Protection of the environment and human health requires consideration of the probability that adverse effects will occur. In the context of PBTs, this requires that the organisms are susceptible to the substance (i.e., that they possess the target receptor(s) for the primary mode of action) and that the exposures experienced by the organism(s) are such that the threshold for toxicity is exceeded. Thus, as for all chemicals, the probability of adverse effects is a product of the combination of susceptibility and exposure. Properties that are important in determining exposures and toxicity for PPPs are discussed below. A number of terms related to $\mathrm{P}, \mathrm{B}$, and $\mathrm{T}$ are used in this paper. For a more 
detailed definition of these terms, readers should see information in Additional file 1.

\section{Persistence, bioaccumulation, and biomagnification}

Exposures to PPPs is dependent on the quantity used (the application rate; see discussion of toxicity below) and the fate of the substance in the environment. Fate, specifically in the context of $\mathrm{P}$ and $\mathrm{B}$, is dependent on the physical and chemical properties of the substance as well as the environment into which it is released. Bioconcentration in aquatic organisms is driven primarily by properties related to $K_{\mathrm{OW}}$ [22]. Bioaccumulation and biomagnification are also driven by $K_{\mathrm{OW}}$ (and $K_{\mathrm{OA}}$ for terrestrial species [23]); however, they also are dependent on $\mathrm{P}$ in that rapid metabolism to less hydrophobic metabolites will reduce the potential for bioaccumulation and biomagnification, the processes of greater concern. The important concept that needs to be considered when assessing exposures is that $\mathrm{P}$ and $\mathrm{B}$ are dependent on the properties of the chemical and its environment. Thus, while basic properties such as $K_{\mathrm{OW}}$ or $K_{\mathrm{OA}}$ may predict bioconcentration, metabolism in organisms [24] or degradation in the environment by processes such as photolysis may negate this, as in the example of the pyrethroid insecticides, which have large $K_{\mathrm{Ow}} \mathrm{S}$ but are not bioaccumulated or biomagnified [25]. Similarly, persistence in one environment should not be extrapolated to other environments. The half-life for many PPPs varies strongly with temperature, and persistence is reduced or increased in various environmental media with increasing or decreasing temperature, respectively. An example is the decrease in half-life of chlorpyrifos in water from 100 days at $15^{\circ} \mathrm{C}$ to 10 days at $35^{\circ} \mathrm{C}$ [26]. The same is true with photolysis, which varies with latitude and season [27], but not always as one may predict. For example, the observed dissipation of triclopyr in a northern lake in Ontario was more rapid than in the southern USA because degradation was primarily photolytic and penetration of light in the clear water of the northern lake was greater than in turbid waters on the southern USA, and day-length was greater in the north [28]. In this regard, photolysis can be a critical process that is particularly relevant to persistence of PPPs, as they are mostly used outdoors where light is abundant and a necessary component of agricultural production. The important concept here is that all environments are not the same and persistence of PPPs needs to be considered in relation to the environment of release and, if significant amounts are transported, in the receiving environment.

\section{Toxicity}

Toxicity is dependent on the chemical and physical properties of the substance, but PPPs are a special case as these chemicals usually have selectivity for the pests they are used to control and their release into the environment is known. Thus, herbicide is generally most toxic to plants and generally least toxic to animals. This selectivity should be considered in the management of risks from PPPs, whether they have PBT properties or not. This may become important in the consideration of toxicity of PPPs in that these chemicals are generally more toxic to the target organisms than large-volume chemicals that are typically used in commerce. The rate of application of PPPs is dependent on potency so that potential exposures in the site of release are normally inversely proportional to the toxicity to the target organism. This relationship results in a more or less constant ratio of toxicity per unit area of use and this is defined on the label of the product. This is an important concept in that the toxicity of PPPs must always be normalized to application (release) rates when assessing $\mathrm{T}$; unfortunately, this concept is not considered when classifying on the basis of a single simple hazard criterion.

\section{Discussion}

Data for use in characterizing $P, B$, and $T$ Availability of data on $P, B$, and $T$ for PPPs

Plant protection products are registered or authorized for use in almost all jurisdictions, and all of these registrations must be supported by a large amount of data. In the EU, this authorization is under the auspices of Regulation 91/414 [29] which is now followed by Regulation $1107 / 2009$ [10], and data on the environmental fate and toxicity to non-target organisms must be provided to regulators and must be evaluated prior to the product being allowed for sale in the market. The testing process is rigorous and provides a much larger amount of data for PPPs than for substances used in other areas, such as those being addressed under the REACH regulations. These data are from studies conducted in the laboratory under approved guidelines as well as from the field and provide verified information on persistence, bioaccumulation, and toxicity. Given the wealth of data available, it is appropriate to use these data to the fullest extent and it is not necessary to use values from in silico models or derived from quantitative structure-activity relationship for the PPPs.

\section{Quality of data}

Quality of data is important when assessing the properties of any substance for the purposes of categorization or assessment of risks. While the use of approved guidelines such as those published by the Organisation for Economic Co-operation and Development (OECD) is important for the purposes of comparisons and ranking, the quality of the conduct of the study is also important. Where multiple data points are available for a substance, data of the best quality must be used. 
Several procedures have been developed for assessing the reliability of data on environmental fate and toxicity that are published in the literature. An internationally accepted procedure was proposed by Klimisch et al. [30], and similar guidelines are used in other jurisdictions [31]. The procedure classifies data from the literature in four categories: reliable without restrictions, reliable with restriction, not reliable, and not assignable. However, registration of PPPs is supported by a large number of studies conducted according to guidelines and under very stringent conditions that ensure the transparency and veracity of the data. Thus, in characterizing PPPs, data from guideline studies such as those of the OECD that are conducted under good laboratory practice (GLP) with quality assurance and quality control (QA/ QC) are also available. Because guidelines studies follow consistent protocols, data can be more reliably compared between compounds and the criteria. In addition, GLP with QA/QC enhances the transparency and veracity of the data [32]. For this reason, these studies are the most preferred; however, non-guideline studies conducted in the spirit of GLP can also be included (Table 2). Therefore, with specific reference to studies required for registration of PPPs and the recommendations of Klimisch et al. [30], selection of data should be in the order indicated below Table 2. Data in ranks 3 and 4 should not be used.

It is important to recognize that some chemicals may possess unusual properties and it may not be possible to characterize $\mathrm{P}, \mathrm{B}$, or $\mathrm{T}$ properties by using standard guideline tests. An example is D5-siloxane which required special non-guideline procedures to compensate for high vapor pressure and high $K_{\mathrm{AW}}$ of the material [33]. Thus, provided the correct hypothesis was tested, the quality of the data can be judged as above.

\section{Multiple data}

Dossiers for PPPs submitted by applicants for registration usually contain reports of several simulation studies for one appropriate environmental medium, e.g., soil, sediment, and water. However, data from non-standardized simulation studies may provide useful information on the temporal behavior of PPPs in an appropriate environment, which might be used for assessing the influence of important environmental conditions on properties such as persistence. In some cases, laboratory tests may not be realistic enough to accurately represent actual bioaccumulation patterns in organisms living in natural ecosystems.

Where multiple data are available, the best quality data should be selected. However, there may be reasons to include lesser quality data, at least to ground-truth predictions, such as the normalization of persistence for differences in temperature between regions. If all data are of equal quality, several options are available. If the worst-case values are less than the cut-off values, then the (PPP) can be removed from further consideration as $\mathrm{P}, \mathrm{B}$, or $\mathrm{T}$. If there is a range of values that cannot be explained by regional or other environmental factors, the median or geometric mean value could be used [34]. For example, the median was used by Beyer and Matthies [35], and Matthies et al. [36] derive soil degradation half-lives for 45 currently used pesticides when more than one simulation test results were available. Alternatively, the distribution of the values could be used in a Monte Carlo process to generate a distribution of probabilities to allow a probabilistic characterization of $\mathrm{P}, \mathrm{B}$, or $\mathrm{T}$.

\section{Weight of evidence}

Ideally, all guidelines and criteria should be based only on scientific evidence. In this sense, the data on $\mathrm{P}, \mathrm{B}$, or $\mathrm{T}$ are all lines of evidence that are brought together to identify substances that are potentially harmful in the environment. This process should be undertaken using a weight of evidence approach where the quality of the data is assessed and the evidence is weighed in a formal and transparent sense. However, the weight of evidence process often is ill-defined or inconsistently applied [37]. In most papers published in the human risk assessment literature, the term was used metaphorically [37]. The same is true for the ecotoxicological literature except work on contaminated sites [38], et seq., rivers [39,40], and in the identification of toxic substances in sediments, and in the assessment of their risks $[41,42]$.

Table 2 Criteria for selection of data for categorization of PPPs

\begin{tabular}{|c|c|c|c|c|c|c|c|}
\hline Rank & $\begin{array}{l}\text { Guideline } \\
\text { study }\end{array}$ & $\begin{array}{l}\text { Non- } \\
\text { guideline }\end{array}$ & $\begin{array}{l}\text { GLP with } \\
\text { QA/QC }\end{array}$ & $\begin{array}{l}\text { Spirit of GLP full } \\
\text { protocol and raw data }\end{array}$ & $\begin{array}{l}\text { Minor issues in the methods } \\
\text { but otherwise clear }\end{array}$ & $\begin{array}{l}\text { Major issues in the } \\
\text { methods or reporting }\end{array}$ & $\begin{array}{l}\text { Reliability of } \\
\text { data (from [30]) }\end{array}$ \\
\hline \multirow[t]{4}{*}{1} & $x$ & & $x$ & & & & \multirow{4}{*}{$\begin{array}{l}\text { Without } \\
\text { restrictions }\end{array}$} \\
\hline & & $x$ & $x$ & & & & \\
\hline & $x$ & & & $x$ & & & \\
\hline & & $x$ & & $x$ & & & \\
\hline 2 & & & & & $x$ & & With restriction \\
\hline 3 & & & & & & $x$ & Not reliable \\
\hline 4 & & & & & & & Not assignable \\
\hline
\end{tabular}


Annex XIII of REACH [5] suggests that in the categorization of PBTs, the weight of evidence approach be used:

A weight-of-evidence determination means that all available information bearing on the identification of a PBT or a $v$ PvB substance is considered together, such as the results of monitoring and modelling, suitable in vitro tests, relevant animal data, information from the application of the category approach (grouping, read-across), (Q)SAR results, human experience such as occupational data and data from accident databases, epidemiological and clinical studies and well documented case reports and observations. The quality and consistency of the data shall be given appropriate weight. The available results regardless of their individual conclusions shall be assembled together in a single weight-of-evidence determination.

Unfortunately the Annex does not specify how these weights should be applied and how they should be aggregated into a total weight of evidence. However, a number of recent papers have provided suggestions as to how this may be done $[43,44]$.

\section{Persistence}

\section{Assessment of $P$ under EC 1107/2009}

There is inconsistency in the criteria used for categorization of various substances under regulations in the EU. The criteria for considering an active substance (PPP), safener, or synergist to be a persistent, bioaccumulative, and toxic substance are laid down in paragraph 3.7.2 of Annex II of Regulation EC 1107/ 2009 [10]. The persistence criterion is fulfilled when the half-life in marine water and sediment, fresh and estuarine water and sediment, and in soil exceeds specific values (see Table 1). It is further noted that 'assessment of persistency in the environment shall be based on available half-life data collected under appropriate conditions, which shall be described by the applicant.' Similarly, in paragraph 3.7.3.1, a very persistent substance (vP) is characterized by longer half-lives in the same environmental media. The term 'half-life' is neither clearly defined nor further specified as to the environmental media considered for assessment. Moreover, the term 'appropriate condition' needs further explanation.

In paragraph 3.7.1 of Annex II [10], persistence is also used as a criterion for the categorization of an active ingredient of a PPP as a persistent organic pollutant (POP). Here, the persistence criterion is fulfilled when there is evidence that the time it takes for degradation of $50 \%$ (DT50) in water, soil, and sediment is greater than specific values. The term "degradation of 50\% (DT50)" is in contrast to Annex D Information Requirements and
Screening Criteria of the Stockholm Convention on Persistent Organic Pollutants, which uses the term 'half-life of a chemical' in water, soil, and sediment [2]. Half-life based on degradation is more appropriate than dissipation (movement and/or partitioning) into another compartment [6].

Regulation EC 1907/2006, the REACH, was amended in March 2011 [5] to take into account the identification of PBT and $\mathrm{vPvB}$ substances to ensure a high level of protection for human health and the environment. In Annex XIII [5], persistence criteria are specified as 'degradation' half-lives, which are identical with those of Annex II of Regulation 1107/2009 [10]. Moreover, information for the assessment of $\mathrm{P}$ and $\mathrm{vP}$ properties to be considered are results from simulation testing on degradation in surface water, soil, and sediment and other information from field studies or monitoring studies, provided that its suitability and reliability can be reasonably demonstrated.

There are three problems associated with the procedures for evaluation of $\mathrm{P}$ as it is implemented under regulation EC 1107/2009 [10]. First, no guidance is given as to how the half-lives in soil, water, and sediment should be derived for comparison with the criteria of Annex II. Second, the selection of the numerical values of the half-life criteria in Annex II is not optimal because they are based on the half-lives of legacy POPs or 'dirty dozen' with highest half-lives in soil and sediment and lowest half-lives in air and water. It is worth noting that the problem of long-range transport, typically in air for POPs, is specifically addressed elsewhere in the Annex II (Section 3.7.1.3) and is the reason for the used half-life in air as a trigger for long-range transport in the POPs Convention. Current-use PPPs have quite different chemical structures than the chlorinated dirty dozen and thus other combinations of half-lives [36]. Moreover, the partitioning of these substances between environmental compartments is not taken into account. PBT assessment is based on intrinsic properties of the chemicals and not on exposure assessment. However, partitioning between compartments is relevant in order to assess the different behavior of the chemical in the different media and, as a consequence, its overall persistence [45]. Third, in contrast to the REACH regulation [5], a weight-of-evidence approach is not part of the PBT assessment. Taking these problems together, it is clear that the possibility exists that some chemicals which are persistent in the environment will not be identified as persistent and vice versa.

\section{Testing for persistence}

Laboratory methods Laboratory simulation studies in an appropriate environmental medium at environmentally realistic conditions are tests that could provide a 
definitive degradation half-life that could be compared directly to the persistence criteria as defined in Annex II of EC 1107/2009 [10]. Such tests allow measurement of biotic and abiotic degradation processes. A correctly conducted study using either the OECD Guidelines for soil [46], water/sediment [47], or water [48], or equivalent SETAC [49], US Environmental Protection Agency [50], or BBA (Federal Biological Research Centre for Agriculture and Forestry, Braunschweig) guidelines $[51,52]$, with the degradation half-life calculated for the appropriate compartment, would allow direct comparison to the criteria. However, even with a correctly conducted study, results can be difficult to interpret, particularly when partitioning between phases and/or aerobic/anaerobic conditions can arise. The use of ${ }^{14} \mathrm{C}$ labeled material under controlled laboratory conditions enables determination of all residues and, by trapping evolved ${ }^{14} \mathrm{CO}_{2}$, the establishment of a complete mass balance.

The simulation tests as described above address the fate and behavior of a substance as it may be expected in the environment including information about partitioning in the test system, primary or complete degradation, adsorption behavior, and route of degradation (degradation products). The endpoints usually addressed are primary or ultimate degradation rate and half-lives or DT50s for the compartments included in the test system as well as the route of degradation, metabolites, and non-extractable residues (NER). In general, NER consist of covalently bound and biogenic residues [53] as well as sequestered or entrapped xenobiotic molecules in structural voids and hydrophobic interiors of micelle-like humic aggregates [54]. The first two fractions are considered to be an integral part of the organic soil or sediment matrix. The third fraction of NER might be reversibly sorbed and slowly released over long time leading to small extractable amounts. This was recently shown by Jablonowsky et al. [55] by means of accelerated solvent extraction and LCMS/MS analysis of atrazine and 2-hydroxy-atrazine in an agriculturally used outdoor lysimeter 22 years after the last application. However, the concentrations were so small that DT50 or half-life estimations would not be quantitatively altered. Moreover, the particular concern of PBT compounds is the combination of the three characteristics, and, in this context the bioavailability, i.e., that they will be present in amounts that are toxic or bioaccumulate is essential [56].

Field methods Terrestrial field dissipation tests under realistic outdoor conditions are triggered in EU regulation 1107/2009 (as well as the outdated EU Directive 91/ 414) if the laboratory half-life of a parent substance exceeds a given trigger value of 60 days. Guidance for outdoor dissipation studies is available $[49,57,58]$.
Dissipation time values in laboratory and field soils are only weakly correlated $\left(0.2<r^{2}<0.3\right)$. This is most likely because laboratory test protocol requires artificial pretreatment of the soil such as drying, sieving, and remoisturizing in comparison to undisturbed conditions in the field. Also, variability in field soil is large and additional processes such as volatilization, photolysis, and leaching also influence dissipation [35]. Loss processes other than biodegradation (and the formation of non-extractable residues) such as volatilization, photodegradation, or leaching out of the analyzed zone need to be reduced in the design of the experiments or considered in the estimation of parameters. Guidance on how to evaluate terrestrial field dissipation studies to obtain biodegradation half-lives is given in Forum for Co-ordination of Pesticide Fate Models and their Use (FOCUS) [59-61] as well as in European Food Safety Authority (EFSA) [62].

In order to use terrestrial field half-lives for exposure modeling following the principles of the EU regulation $1107 / 2009$, normalized biodegradation half-lives are required. Guidance on normalization of field half-lives to reference conditions (usually $20^{\circ} \mathrm{C}$ and moisture at $\mathrm{pF} 2$ ) is given in FOCUS [60] and EFSA [62]. The normalized biodegradation rates from field studies corrected for all other loss processes (e.g., volatility and leaching) are directly comparable with degradation rates obtained from laboratory studies as described above and therefore appropriate to be compared with the $\mathrm{P}$ criterion for soil. In contrast to terrestrial field dissipation studies, no guidance is available for aquatic outdoor studies.

\section{Simulation test for soil}

Pesticides have to be tested on their biodegradability in soil by simulation tests in laboratory and field. Guidelines from various institutions have been issued for simulation testing under aerobic as well as anaerobic conditions (e.g., [46,51]). In soil simulation tests, soil samples are incubated with the test compound and analyzed for the parent compound and transformation products after appropriate time intervals. The use of ${ }^{14} \mathrm{C}$-labeled material under controlled laboratory conditions enables determination of all residues and, by trapping evolved ${ }^{14} \mathrm{CO}_{2}$, the establishment of a complete mass balance. The times after $50 \%$ or $90 \%$ of the applied quantity have disappeared (or dissipated) are called DT50 and DT90, respectively. They are used as regulatory endpoints to quantify removal dynamics and to assess persistence in soil. Moreover, the percentages of applied radioactivity (\%AR) present as metabolite(s), mineralized ${ }^{14} \mathrm{CO}_{2}$, and NER after 100 days of incubation are reported and used as additional information for assessment of pesticide exposure. However, these three additional endpoints cannot be used in PBT assessment 
because they do not provide data for comparison with $\mathrm{P}$ criteria.

The report of the FOCUS work group on degradation kinetics [60] describes kinetic models to meet the requirements for registration of pesticides in the EU. The threecompartment model consists of an input compartment (parent compound), a metabolite compartment (sometimes further compartments of secondary metabolites) and an output compartment (sink) including evolved $\mathrm{CO}_{2}$ and NER. Disappearance of the test substance is described by primary degradation and loss to the sink compartment, which is also fed by reaction of metabolite(s). Thus, mineralization and formation of NER are not distinguished as separate processes. However, simulation tests provide time series of NER and evolved ${ }^{14} \mathrm{CO}_{2}$, which can explicitly be considered for fitting kinetic model parameters.

The FOCUS model was extended by Matthies et al. [63] by taking into account mineralization and NER as separate pools. They applied their kinetic four-pool model to ${ }^{14} \mathrm{C}$-labeled residues measured by aerobic soil incubation studies reported in dossiers submitted for authorization of eight PPPs and determined parameters for first-order kinetic rate constants by fitting time series from 40 studies. Correlation of kinetic rate constants for primary degradation and formation of NER from parent pesticide suggested a common mechanism, presumably co-metabolic microbial activity for both processes. Recently, Loos et al. [64] verified these conclusions by applying the same four-pool kinetic model to a data set of degradation time series for 73 pesticides. They also found a high correlation between primary degradation and formation of NER from the parent compound, indicating that the actual degradation half-lives in soil typically do not exceed disappearance half-lives by more than a factor of 2. They evaluated only data derived with one standard soil (Speyer 2.2), which reduced the influence of the natural soil variability. A difference in the persistence of a factor of 2 is small compared to the observed natural variability of soil degradation half-lives. FOCUS [60] combines all degradative loss processes of the parent compound, i.e., primary degradation, mineralization, and formation of NER, into a DegT50 which is used for comparison with the $\mathrm{P} / \mathrm{vP}$ criteria of $120 / 180$ days in soil.

\section{Simulation test for sediment}

In the framework of the registration of pesticides, experiments in standardized water-sediment test systems are required for substances which are not readily biodegradable. These experiments are useful to evaluate the degradation of the substances under realistic and fieldrelevant conditions in the sediment $[47,49,52]$. Detailed procedures are available for conducting these studies and for interpreting the results $[60,65]$.
It must also be pointed out that the experimental setup allows for settling of suspended solids during the acclimatization phase. Thus, the microbial biomass in the water phase during the experiment is most likely very small and biodegradation is negligible in the bulk water phase. This implies that true loss processes largely occur in the sediment. In addition to biodegradation, formation of bound residue is most likely responsible for the long-term decrease of the active ingredient in the sediment as well as in the bulk water phase due to the partitioning between both phases. DT50 for the whole system characterizes degradation as well as formation of bound residues in the sediment and is used as a conservative approximation of the half-life in sediment for comparison with the P criteria.

\section{Simulation test for surface water}

As the OECD test for degradation in surface water OECD method 309 [48] is a new data requirement under EU Regulation 1107/2009 EEC [10], there is not yet much experience with this simulation test. Since almost all PPPs are intentionally stable to hydrolysis, it is expected that many substances, even if they have very short half-lives in 'real-world' natural aqueous systems, will be shown to be persistent in this test. The unrealistic conditions (no photolysis, no partitioning to sediment, and little microbial activity) used in the OECD 309 test will result in very long half-lives. It is therefore questionable if this test can provide a realistic measure of persistence a substance in a natural aquatic environment.

Direct photolysis is an important removal process from the water phase. Only quanta of UV/visible light (290 to $800 \mathrm{~nm}$ ) are energetic enough to break bonds between atoms in a molecule. As a consequence, chemicals that absorb light significantly in this region can undergo direct photolysis in the water phase. Several guidelines for the study of photolysis of PPPs are available [49,66-69].

Indirect photolysis in natural water is tested for in the same way as described above, except that water from a natural system is used instead of an aqueous buffer system. There is no requirement regarding the water quality parameters, but it has to be taken from a natural source, which has to be described properly. The study is conducted under sterile conditions with a dark control in parallel. The only existing guideline is from Japan [69]; an OECD draft was in preparation but has never been finalized. For European registration, a water/sediment study in the presence of realistic intensity of light that is representative of the outdoor spectrum of sunlight appropriate to the intended use of the PPP (latitude and length of day in relation to season of use) could be used to obtain more realistic information about degradation in the aqueous system under natural conditions, where sunlight and photosynthetic organisms are present. 
If a PPP is photolytically and hydrolytically stable, i.e., failed the $\mathrm{P} / \mathrm{vP}$ criteria in water alone, partitioning into sediment may be fast enough to allow degradation in sediment. Partitioning into sediment is measured in the water/sediment simulation test using OECD method 308 [47] and reported as time to $50 \%$ dissipation (a combination of partitioning and degradation). This DT50 describes the residence time of a PPP in the water phase and, thus, its availability for bioaccumulation into and adverse effects on water-column organisms. In particular for PPPs that have a large $K_{\mathrm{OC}}$, partitioning into the sediment and degradation there (including formation of NER) is the dominant removal process. For such substances, the DT50 from water approximates the half-life in water and provides a measure for comparing it with the $\mathrm{P} / \mathrm{vP}$ criteria in water. Even if the adsorption to sediments is reversible, the partitioning of these types of compounds is strongly towards the adsorbed phase unless the desorbed chemical is degraded in the water phase. The key point is that less chemical is available to organisms for uptake and/or bioaccumulation.

\section{Normalization and/or extrapolation to other conditions and/or scenarios}

Soil half-lives derived from time series data from laboratory simulation and field studies show large variability between different tests. Extrapolation of such results to conditions other than those used in the test (e.g., average environmental conditions) is a critical step that would require detailed knowledge about the effect of sorption and consideration of the large natural variability of biomass activity and biological degradation potential for the compounds of interest. Normalization for temperature and soil moisture is a common procedure in characterizing $\mathrm{P}$ and is required to extrapolate degradation rates to different scenarios. For the most part, normalization reduces the variability of field degradation rates measured under extreme conditions of temperature and moisture content. In order to compare field degradation rates with a single trigger value, normalization could aid arrival at a more conclusive decision. If normalization is not applied, differences in P in the field could be due to the time of application e.g., spring versus autumn. Normalization is usually not required for assessment of $\mathrm{P}$ in water and sediment because half-lives are mostly measured under laboratory standard conditions, e.g., room temperature.

Corrections for differences in temperature and soil moisture also can be made. The temperature dependence of the soil degradation half-life can be calculated by the Arrhenius equation. The ratio of degradation halflives at a $10^{\circ} \mathrm{C}$ higher temperature is defined as the factor Q10. EFSA [70] re-evaluated the default Q10 value of 2.2 derived by the FOCUS Work Group1 [71] and recommended that extrapolation of half-lives should only use the updated default activation energy of $65.4 \mathrm{~kJ}$ mole $^{-1}$ and a Q10 of 2.58. Soil moisture can have a significant influence on microbial activity and on bioavailability of PPPs and thus on half-lives of degradation in soil. Half-lives can be corrected for moisture content of soils by the methods proposed by FOCUS [60].

\section{Bioaccumulation}

\section{Assessment of B under EC 1107/2009}

All living organisms take up chemicals from the environment. The concentration that may be attained within tissues is the combined result of uptake and clearance processes that, in steady state conditions, determine the bioconcentration and/or bioaccumulation factor (BCF/ BAF). By stopping exposure, the clearance process may be studied by evaluating the clearance time (CT) (e.g., CT50 or CT95, the time needed to achieve $50 \%$ or $95 \%$ dissipation in an organism). Clearance time may be measured using the OECD guideline for bioaccumulation testing OECD method 305, [72] and should be considered as a necessary endpoint as this can be better used to estimate the steady state BCF. Specific values for CT have not yet been proposed. Obviously, the relevance of these processes and the patterns of uptake are substantially different in the different organisms, depending upon their biological characteristics, their ecological and trophic role, the type of environment (aquatic or terrestrial), and the physical and chemical properties of the PPP.

In primary producers, only bioconcentration processes occur. Uptake of chemicals by algae and aquatic plants depends on diffusion from water through plant (or cell) surface or from sediment pore water through the surface of the root. Similar patterns occur in terrestrial plants; root uptake from soil pore water and foliar uptake from air. However, there is enough experimental evidence demonstrating that for lipophilic and semi-volatile chemicals, foliar uptake is the most relevant route of uptake $[73,74]$. Systemic pesticides can be transported within plants. However, the mechanisms of absorption from roots or foliage are the same mechanisms as for bioconcentration.

In animals, all processes (bioconcentration, bioaccumulation, and biomagnification) are possible, but uptake patterns are different in relation to the type of environment (aquatic and terrestrial) and the trophic role of the organism.

In aquatic animals, bioconcentration and uptake through respiratory surfaces are often the most important processes. For freshwater macrobenthic invertebrates, it has been shown that concentration of chlorinated lipophilic chemicals is not related to the position in the food web, indicating that bioaccumulation through food and biomagnification are negligible in comparison to bioconcentration. This could be explained by the 
small size and the large surface/volume ratio of these organisms making bioconcentration the prevailing process [75]. Bioaccumulation through food and biomagnification via the food chain are the most relevant routes of exposures in fish [22] and become more important as $\log K_{\mathrm{OW}}$ increases above 5 . Therefore, BCF is not the most suitable parameter for quantifying biomagnification in the aquatic food web and the biomagnification factor (BMF) or the trophic magnification factor (TMF) is preferred as the best measure [76-79]. However, there is no criterion for BMF or TMF in the regulations (Table 1). Other measures of bioconcentration and bioaccumulation such as BCF from soils and the biota-sediment accumulation factor (BSAF) may be more difficult to use as they are dependent on the properties of the matrix. However, they might be useful to address bioaccumulation from matrices that are more relevant for the compound. They could be normalized to lipid content of the organism and concentration of organic carbon in the sediment $[80,81]$, but criteria are not yet developed for these measures.

The substantial differences in bioaccumulation/ biomagnification processes between water-respiring and air-respiring organisms have been highlighted by Gobas et al. [76]. In terrestrial animals in general, intake via food is the dominant route of exposure.

Bioconcentration of lipophilic chemicals may be predicted through a simple relationship with $K_{\mathrm{OW}}$ discussed in [22]:

$$
\operatorname{logBCF}=a+b \log K_{\mathrm{OW}}
$$

The use of the relationship with $K_{\mathrm{Ow}}$ is proposed by Regulation 253/2011 (REACH) [5] as a preliminary screening procedure for $\mathrm{PBT}$ or $\mathrm{vPvB}$ categorization but a criterion is not provided in the Regulation. The European Chemical Agency (ECHA) proposed the value of $\log K_{\mathrm{OW}}>4.5$ as a criterion for $\mathrm{B}$ [82]. However, $K_{\mathrm{OW}}$ does not account for metabolic transformation and active excretion processes [24]. Therefore, false positives are highly probable and $K_{\mathrm{OW}}$ must be assumed only as an indicator of worst-case conditions of the 'potential' for bioconcentration. More complex models, based on several molecular properties and descriptors, have been recently developed [83-85]. These models are more powerful than the simple relationship with $K_{\text {Ow; }}$; however, with the exception of EPISUITE 4.1 [83], they are limited to prediction of bioconcentration and do not consider biotransformation and/ or excretion. As bioconcentration studies are required for registration of PPPs with a $\log K_{\mathrm{OW}}$ of $>3$, modeling or extrapolation of BCF from properties such as $K_{\mathrm{OW}}$ is not necessary.

\section{Testing for bioaccumulation}

Laboratory methods Measures of BCF for assessment against the criteria are usually derived from laboratory tests in controlled conditions. The only officially accepted method for measuring BCF is the bioconcentration flowthrough fish test OECD method 305 [72]. However, there is evidence indicating that the results of laboratory tests may be substantially different, sometimes orders of magnitude from the results of field studies [86]. Assessing bioaccumulation through laboratory tests presents the following several challenges:

- Testing of chemicals with extremely low solubility is not easy in aquatic systems and many sources of error, such as adsorption to the test containers, are possible. Steady state is often not established due to the slow uptake process.

- Bioconcentration data do not necessarily predict biomagnification processes.

- Laboratory tests usually measure bioconcentration; testing bioaccumulation through food may be more relevant, particularly for compounds with low water solubility. The new version of OECD method 305 [72] accounts for dietary exposure in fish; however, at present there are no trigger values given in the PPP regulation for this route of exposure.

- There is experimental evidence indicating that bioaccumulation patterns in terrestrial food webs may be substantially different from those in aquatic food webs $[23,76]$. However, at present, there are no trigger values for this route of exposure in the PPP regulation.

Field methods Considering the limitations and weaknesses of laboratory bioconcentration tests, the TMF has been proposed as the best and most reliable tool for assessing bioaccumulation and biomagnification of chemicals $[24,76]$. However, at this time, reliable TMF values need to be characterized from field studies on chemicals that have been present in the environment for enough time to allow the achievement of equilibrium in natural food webs. Assessing TMF values through laboratory experiments in controlled conditions may be too complex, expensive, and time consuming to be realistically applicable. It follows that TMFs measured in the environment are a suitable tool for the evaluation of chemicals which have been in use for some time, but are less useful for the PBT categorization of new chemical substances under REACH or new PPPs under EU Regulation 1107/ 2009 [10]. 


\section{Toxicity}

\section{Assessment of T under EC 1107/2009}

For PPPs and biocides, the toxicity criterion presents challenges because they are toxic chemicals, which, by definition, are produced and used for the control of target species (pests). All PPPs will be specifically toxic to at least one group of organisms. Very few PPPs are highly specific for a few target species only. In most cases, toxic effects comparable to those for target species occur in non-target species belonging to the same taxonomic group. For example, insecticides are toxic to the target insects and often to other arthropods as well. Also, they may present a risk to non-target beneficial insects, such as pollinators. For other classes of chemicals, toxicity may occur in taxonomic groups other than the target species. For example, pyrethroid insecticides have low toxicity for mammals but, because of differences in absorption and metabolism, are toxic to fish. In other cases, the toxicological mode of action may be the inhibtion of physiologic and metabolic functions common to many taxonomic groups. For example, organophosphorus and carbamate insecticides are inhibitors of acetylcholinesterase, a key enzyme involved in nervous transmission in most animals. Although PPPs are highly toxic to one or more group of organisms (pests), they do vary in toxicity. This variation in toxicity is considered in the recommended rates of application of PPPs in that the more effective they are, the lower the rate of application. Thus, it is inappropriate to use a fixed criterion of toxicity for categorization, such as the $10 \mu \mathrm{g} / \mathrm{L}$ recommended in Regulation $1107 / 2009$ [10] as this will lead to false negatives and false positives. However, in another context, a fixed threshold based on intrinsic hazard may be useful for prioritization for refined assessment of risk.

The philosophy of the PBT concept, according to Regulation $1107 / 2009$ [10], is that a chemical with high persistence and bioaccumulation capability may be transferred in the food web, reaching concentrations that may present a danger to organisms at higher trophic levels [76]. Even if this concept is implicitly accepted by the procedure which requires that all the three criteria $(\mathrm{P}, \mathrm{B}$, and $\mathrm{T})$ must be fulfilled, it is never explicitly mentioned in official regulatory documents. This may lead to a misleading interpretation of the toxicity trigger, considering that lower trophic levels (i.e., algae and plants) are not organisms of high concern for assessment of biomagnification of PPPs.

According to Regulation 1107/2009 [10] for categorization of PPPs, the criteria for $\mathrm{T}$ are: An active substance, safener or synergist fulfills the toxicity criterion where:

- The long-term no-observed effect concentration for marine or freshwater organisms is less than $0,01 \mathrm{mg} / \mathrm{l}$,
- The substance is classified as carcinogenic (category $1 \mathrm{~A}$ or $1 \mathrm{~B}$ ), mutagenic (category $1 \mathrm{~A}$ or $1 \mathrm{~B}$ ), or toxic for reproduction (category $1 \mathrm{~A}, 1 \mathrm{~B}$ or 2$)^{\mathrm{a}}$ pursuant to Regulation (EC) No 1272/2008, or

- There is other evidence of chronic toxicity, as identified by the classification STOT RE 1 or STOT RE 2 pursuant to Regulation (EC) No 1272/2008.

It is assumed that the criteria are relevant for the standard aquatic studies and based on standard endpoints required in such guideline tests. However, it is not clear if non-standard studies and non-standard endpoints could be used in categorization, but they could be used as supporting data in a WoE approach. Furthermore, the ecotoxicity endpoints apply only to aquatic organisms and terrestrial organisms are not considered.

The $\mathrm{T}$ criterion for categorization of PBT provides a toxicity threshold but does not indicate a specific kind of organism, although the use of the plural 'organisms' suggests that data from more than one species are to be considered and that it refers to the three trophic levels assumed to be representative of aquatic systems in traditional risk assessment procedures. In addition, data from multiple studies on the same species may need to be dealt with as is discussed for multiple data above. Where toxicity data from multiple species are available, the fact that most PPPs are selective for certain groups of organisms must also be considered. Here the group(s) that is(are) most sensitive should be selected but the protection goals for this group need to be considered in this choice. For example, protection goals for long-lived and socially valued animals such as fish would be different from algae and/or short-lived invertebrates with a high potential for rapid recovery.

\section{Testing for toxicity}

Laboratory methods Several guideline methods are available from OECD, US Environmental Protection Agency, and others to assess short- and long-term effects of PPPs on aquatic organisms. Many other test methods dealing with invertebrates or fish, even if not officially recognized by regulatory organizations, are internationally accepted by the scientific community. All these methods are suitable for producing no observed effect concentrations (NOECs) according to the requirements of the PBT categorization. Some of these procedures (the Daphnia magna reproduction test) may also be used as screening tests for reproductive toxicity [87-90].

Testing on terrestrial organisms is not explicitly required as a criterion for PBT chemicals. However, suitable toxicity methods for assessing NOECs on several taxonomic groups of terrestrial animals (from invertebrates to 
higher vertebrates) are available in the literature, including officially accepted test procedures e.g., in [91-93]. In the case of persistence which is specific to soils in the terrestrial environment, it may be more appropriate to combine this with an evaluation of bioaccumulation and toxicity in terrestrial organisms; however, there are no triggers provided for such an assessment.

Field methods Observations from semi-field or mesocosm studies can provide additional data for assessing $\mathrm{T}$, particularly under realistic environmental conditions. This approach is not specifically mentioned among the criteria for PBT categorization. However, it is commonly accepted in ecological risk assessment procedures, as well for the official procedures for assessing predicted no-effect concentration (PNEC) [94] and procedures for assessment of effects in microcosms have been developed [12]. The use of toxicity data from semi-field and ecosystem-level (cosm) studies is not mentioned in the criteria for categorization.

Species sensitivity distributions The use of species sensitivity distributions (SSDs) is not mentioned among the criteria for PBT categorization even if it is recognized as a powerful tool for ecological risk assessment, where sufficient reliable data are available [94]. If there are sufficient toxicity data for species in different taxonomic groups or data on different species within a relevant (i.e., sensitive) group, a SSD $[95,96]$ can be developed and used for the calculation of the HC5 (hazardous concentration for protection of $95 \%$ of the species). The use of the SSD approach, if applicable, presents several important advantages: It is probabilistic; the confidence interval is statistically derived, and is therefore less biased than a deterministic approach, which may be influenced by a heterogeneous distribution of data; it reduces the effect of outliers; and it provides an insight of the effects on the whole community. If insufficient data are available for $n$ SSD ( $\geq 8$ species), the value for the most sensitive relevant species can be used.

\section{Conclusions}

The function of categorization of PPPs under regulation $1107 / 2009$ [10] is to screen out products from further consideration if they do not possess PBT properties. Unlike the weight of evidence process recommended in $\mathrm{REACH}$ [5], there is presently no process for carrying out a more refined assessment of those PPPs that are identified as having PBT properties or not. In fact, the very few criteria used and the use of simple trigger values for the categorization of complex processes are an obvious contrast to the detailed assessments carried out in other regulations that are relevant to PPPs, such as the previous regulation, Directive 91/414 [97].
Large experimental data sets are available to classify PPPs in terms of persistence. Multiple laboratory and field studies under various environmental conditions are carried out to estimate the influence of the natural variability on degradation processes. Half-lives are determined under conditions that eliminate or control for dissipation via volatilization, leaching, etc., and can be used for comparison with the persistence trigger values thus ensuring a robust and safe categorization of PPPs. Unfortunately, the current process in the regulations does not take full advantage of the large amount of data available. For example, photolysis data are not used to classify persistence when, for some products, this could be a major pathway of degradation.

The criteria for categorization of PPPs as bioaccumulative [10] are principally focused on aquatic systems where pesticides are not routinely applied. The triggers for bioaccumulation are based on processes that are unique to aquatic systems and do not address biomagnification in terrestrial systems. They also do not address biomagnification of chemicals that move from aquatic systems to terrestrial organisms, such as in piscivorious birds that consume aquatic organisms.

Similarly, the criterion for categorization of PPPs as toxic [10] is principally based on aquatic data and lacks appropriate triggers for categorization of toxicity to terrestrial organisms. There is generally a considerable data base on (eco)toxicity available for PPPs, and more guidance how to consider this in the PBT evaluation will be helpful.

\section{Recommendations}

In the process of carrying out this review, several areas were identified where more guidance to the system of categorization of PPPs under Regulation 1107/2009 [10] would be valuable. We recognize that changes to regulations are not easily made but believe that significant improvements in accuracy can be achieved by appropriately selecting the relevant data to be used in the cut-off process without violating the intent and content of the regulation. In this way, false negatives and false positives can be reduced while still identifying the critical compounds with greater certainty.

Weight of evidence should be used in categorization of PPPs under Regulation 1107/2009. Others [1] have noted the significant inconsistencies in the criteria used for categorization of PBTs between the regulations for PPPs [10] and those used by REACH [5]. A key difference between these is the recommendation for the use of weight of evidence for assessment of properties relevant to the categorization of substances for $\mathrm{P}, \mathrm{B}$, and $\mathrm{T}$. We believe that the use of a formal, quantitative, and transparent process of weight of evidence should be included in the guidance for the selection of appropriate 
data and how these are compared to the criteria. We recommend that the analysis of weight of evidence be hypothesis-driven and evaluate the relevance and responses quantitatively such as has been suggested by Borgert et al. [44].

Additional lines of evidence need to be considered when assessing persistence in water and sediments. We believe that the persistence in a water-only test does not provide useful data for assessing persistence in natural waters in agricultural areas where sediments are always present. Since PPPs are mostly used outdoors, we believe that additional lines of evidence such as those provided by the water-sediment test for persistence and photolysis should be considered together with laboratory data. Good procedures for measuring persistence of PPPs in soil and water under field conditions are available and these provide additional and more relevant information. In some cases, it may be possible to measure toxicity and bioaccumulation under more realistic conditions in field and semi-field systems and these lines of evidence should also be included in the guidance.

Quality of data is addressed above and, fortunately, much of the data for $\mathrm{P}, \mathrm{B}$, and $\mathrm{T}$ is conducted using standardized guidelines and under GLP with QA/QC. These data are produced in a transparent and verifiable manner and have greater veracity than many studies published in the open literature. This should be recognized in the guidance for selecting the data for categorization of PPPs under Regulation 1107/2009.

For data of acceptable quality from multiple studies, it was suggested above that these be combined as an arithmetic or geometric mean, depending on the distribution of the data (normal or log-normal). Because degradation processes in the environment are first-order or pseudofirst-order, the geometric mean of half-lives from multiple studies is recommended for comparison to criteria for $\mathrm{P}$. Alternatively, at least in a second tier of characterization, the distribution of values can be used in Monte Carlo procedures, provided that dependencies and covariates are considered. For data on toxicity from multiple species, the use of centiles, such as the HC5, is recommended but with appropriate attention to the protection goals. Since the focus of the regulation is combination of $\mathrm{P}, \mathrm{B}$, and $\mathrm{T}$ for organisms at higher trophic levels [76], plants are usually not the particular concern for biomagnification of PPPs.

For persistence in soils, half-lives from field studies should be included, if available, conducted under standardized conditions and evaluated as proposed by EFSA [62]. Photolysis on soil is a relevant degradation pathway and should be taken into account. Normalization to reference conditions (e.g., temperature of $20^{\circ} \mathrm{C}$ and soil moisture at pF 2) as proposed by FOCUS [60] is recommended.

For laboratory tests of persistence in water-sediment, it is recommended that two different systems be used.
First, the water-sediment test OECD method 308 [47] is recommended to determine the DT50 of the total system as a conservative value for the half-life in sediment. Secondly, for water, it is recommended that laboratory tests on direct and/or indirect aquatic photolysis be used to determine the abiotic half-life in the water phase. If a PPP is photolytically and hydrolytically stable, i.e., failed the $\mathrm{P} / \mathrm{vP}$ criteria in water, the partitioning into sediment may be rapid enough to allow degradation in sediment. Transfer into sediment is determined with the watersediment simulation test (OECD 308) and reported as time for disappearance of $50 \%$, i.e., DT50, which can be used as an appropriate measure for comparison with the criteria for $\mathrm{P} / \mathrm{vP}$ in water.

The objective of setting criteria for persistence in the environment is to avoid situations where the substance will accumulate to greater and greater amounts over time. With this in mind, we recommend that consideration be given to the use of selection criterion for overall persistence, $\mathrm{P}_{\mathrm{OV}}$ [36]. In actuality, this is what is recommended for water-sediment above, but this argument could be expanded to persistence in all media. We recommend that should be considered and, if included, screening criteria for this parameter should be developed and included in the guidelines.

Some substances strongly adsorb to surfaces such as sediments and are protected from chemical or biological degradation while adsorbed. Thus, they may be classified as persistent. Provided that these substances can be degraded if and when they desorb, this should not be considered as an indication of P or vP. This should also be considered in the criteria and guidelines for assessment of $\mathrm{P}$.

The criterion for bioaccumulation in Regulation $1107 / 2009$ [10] is a BCF of 2,000 and in the REACH Regulation 253/2011 [5], the criteria for $\mathrm{B}$ and $\mathrm{vB}$ are BCF/BAFs in aquatic species of 2,000 and 5,000, respectively (Table 1 ). The concentrations in animals are expressed as fresh weight (without any normalization), but this is not explicitly stated in the regulations. These are the only numerical triggers proposed in either of the regulations. We recommend that if BCF is used as a criterion, it should be derived from rates of depuration as measured in a bioaccumulation test such as OECD method 305 [72], as this provides a better and more realistic estimate of the steady state BCF. As field data better incorporate environmental factors that may interfere with bioaccumulation patterns in natural ecosystems, they should be considered. We recommend that all relevant information be used in a weight of evidence approach to determine if the criteria for bioaccumulation are met.

Other criteria for B should be considered as well. For example, in the REACH Regulation 253/2011 additional 
qualitative, non-numerical criteria are mentioned as follows:

(b) Other information on the bioaccumulation potential provided that its suitability and reliability can be reasonably demonstrated, such as:

- Results from a bioaccumulation study in terrestrial species;

- Data from scientific analysis of human body fluids or tissues, such as blood, milk, or fat;

- Detection of elevated levels in biota, in particular in endangered species or in vulnerable populations, compared to levels in their surrounding environment;

- Results from a chronic toxicity study on animals;

- Assessment of the toxicokinetic behaviour of the substance;

(c) Information on the ability of the substance to biomagnify in the food chain, where possible expressed by biomagnification factors or trophic magnification factors.

As these non-numerical criteria for bioaccumulation are vague and difficult to apply transparently, guidance should be developed. No indication is provided on the type of endpoints to be assessed, of the methods to be used, or of the approach (laboratory or field) to be applied. Moreover, being only qualitative indications, no triggers are proposed for categorization.

Suitable criteria for bioconcentration from soils and $B S A F$ from sediments need to be developed and should incorporate appropriate normalization procedures to account for the influence of the matrix. If data are available for BMF (bioaccumulation between trophic levels) these could be used as a criterion. A BMF of $<1$ would be indicative of no biomagnification. As discussed above, a trophic magnification factor (TMF) is the best indicator of bioaccumulation in food chains as it integrates across all trophic levels and describes the overall result of all accumulation patterns. Generally, TMFs can only be measured after a substance has been used in the environment for enough time to allow equilibrium across trophic levels to become established. A TMF of $<1$ (log TMF $<0$ ) would indicate lack of bioaccumulation in the food web. An alternative approach to characterizing TMF in a prospective way would be to make use of food-web model ecosystems such as those used by Metcalf et al. [98] to provide a physical model of trophic transfer (algae-arthropods-fish) and an estimate of magnification in the food-chain. If a well-understood internal standard such as polychlorinated biphenyls (PCB) PCB 153 or PCB 180 was included with the chemical of concern, a calibrated relative TMF [33] could be measured and used as an alternative criterion to BCF.
The criteria for toxicity of terrestrial organisms are not provided either in Regulation 1107/2009 [10] or the REACH Regulation 253/2011 [5]. If a substance is persistent in the aquatic environment, bioaccumulation and toxicity are relevant and assessment of PBT will proceed. If a substance is not persistent in an aquatic environment but is in the terrestrial environment, we recommend that criteria for $\mathrm{B}$ and $\mathrm{T}$ be developed.

The evaluation PBT should consider the overall environment, integrating all of the information available. Unfortunately, the present triggers provide a mix of individual compartments; toxicity and bioaccumulation are only addressed for the aquatic environment while persistence incorporates addition triggers for the terrestrial environment. This could lead to erroneous categorization. For example, if a substance is only persistent under specific conditions in one compartment, such as in soil under dry or cold conditions this should be taken into account in the overall assessment of PBT.

Further, it is recommended that guidance for categorization of PPPs under Regulation 1272/2008 include $a$ decision-tree for selection and application of the criteria.

\section{Endnote}

${ }^{a}$ Note that although endocrine disruption is not yet defined in these classifications, it is used as a cut-off criterion separately and is considered in the registration process. It is therefore not considered here in detail.

\section{Additional file}

Additional file 1: Supplemental information for Solomon et al. 2013. The additional file provides definitions of a number of terms that we have used in the main text of the paper. For a more complete list of terms and definitions that are relevant to PPPS, please refer to IUPAC glossary of terms.

\section{Abbreviations}

B: bioaccumulative; BAF: bioaccumulation factor; BCF: bioconcentration factor; BMF: biomagnification factor; BSAF: biota-sediment accumulation factor; CT95: The time needed to achieve a 95\% dissipation of a chemical in an organism; DegT50: time for 50\% degradation; DT50: time for 50\% dissipation or disappearance; DT90: time for $90 \%$ dissipation or disappearance; HC5: hazardous concentration for protection of $95 \%$ of the species; $K_{\mathrm{Oc}}$ : water-soil partition coefficient corrected for the amount of organic carbon in the soil; Kow: octanol-water partition coefficient; LRT: long-range transport; NER: non-extractable residues; P: persistent; PBT: persistent bioaccumulative, and toxic; PNEC: predicted no-effect concentration; POP: persistent organic pollutant; $\mathrm{P}_{\text {ov }}$ : overall persistence in all compartments; PPP: plant protection product; REACH: Registration Evaluation, Authorisation and Restriction of Chemicals; T: toxic; TMF: trophic magnification factor; $v B$ : very bioaccumulative; $v P$ : very persistent; WFD: Water Framework Directive.

\section{Competing interests}

Funding for this assessment was provided by BASF (Germany). The opinions expressed in this paper are those of the authors alone and the authors declare no competing financial or non-financial interests. 


\section{Authors' contributions}

The authors MV, MM, and KS contributed equally to the ideas and writing of the paper. KS formatted and prepared the paper for submission. All authors read and approved the final manuscript.

\begin{abstract}
Author details
${ }^{1}$ Centre for Toxicology, School of Environmental Sciences, University of Guelph, 2120 EC Bovey Building, Gordon Street, Guelph, Ontario N1G 2W1, Canada. ${ }^{2}$ Institute of Environmental Systems Research (USF), University of Osnabrück, Osnabrück D-49069, Germany. ${ }^{3}$ Department of Earth and Environmental Sciences (DISAT), University of Milano Bicocca, Piazza della Scienza 1, Milan 20126, Italy.
\end{abstract}

Received: 6 August 2012 Accepted: 18 February 2013

Published: 1 May 2013

\section{References}

1. Moermond C, Janssen M, De Knecht J, Montforts M, Peijnenburg W, Zweers P, Sijm D: PBT assessment using the revised Annex XIII of REACH - a comparison with other regulatory frameworks. Integr Environ Assess Manag 2011, 8:359-371.

2. United Nations Environmental Programme: Stockholm Convention on Persistent Organic Pollutants. Geneva, Switzerland: Secretariat of the Stockholm Convention; 2001:43. http://chm.pops.int/Convention/tabid/54/ language/en-US/Default.aspx.

3. United Nations Economic Commission for Europe: Protocol to the 1979 Convention on Long-Range Transboundary Air Pollution on Persistent Organic Pollutants. Geneva: United Nations Economic Commission for Europe; 1998:49. http://www.unece.org/env//rtap/full\%20text/1998.POPs.e.pdf

4. European Community: Regulation (EC) no 850/2004 of the European Parliament and of the Council of 29 April 2004 on Persistent Organic Pollutants and Amending Directive 79/117/EEC, consolidated text as of August 25, 2010. Brussels: The European Parliament and the Council of the European Union; 2004:30. http://eur-lex.europa.eu/LexUriServ/LexUriServ.do? uri=CONSLEG:2004R0850:20100826:EN:PDF

5. Community E: Regulation (EU) no 253/2011 of 15 March 2011 amending Regulation (EC) no 1907/2006 of the European Parliament and of the Council on the Registration, Evaluation, Authorisation and Restriction of Chemicals (REACH) as regards Annex XIII. Off J Europ Commun 2011, 54:7-12.

6. United Nations Environmental Programme: The Development of ScienceBased Criteria and a Procedure for Identifying Additional Persistent Organic Pollutants as Candidates for Future International Action. Vienna: Criteria Expert Group for Persistent Organic Pollutants of UNEP; 1999. http://chm pops.int/Convention/HistoryNegotiations/tabid/62/Default.aspx.

7. Environment Canada: Toxic Substances Management Policy - Persistence and Bioaccumulation Criteria. Final Report of the ad hoc Science Group on Criteria. Ottawa: Environment Canada; 1995:26.

8. Environment Canada: Toxic Substances Management Policy. Ottawa: Environment Canada; 1995:18. http://www.ec.gc.ca/Publications/2EE9E1E8-1DC4-4886-93B1D67A085FBAA3\%5CToxic-Substances-Management-Policy.pdf.

9. Ritter L, Solomon KR, Forget J, Stemeroff M, O'Leary C: A Review of Selected Persistent Organic Pollutants. DDT-Aldrin-Dieldrin-Endrin-Chlordane-HeptachlorHexachlorobenzene-Mirex-Toxaphene-Polychlorinated biphenyls-Dioxins and Furans. Review prepared for IPCS. Geneva: International Programme on Chemical Safety (IPCS) of the United Nations; 1995:149. http://www.who.int/ ipcs/assessment/en/pcs_95_39_2004_05_13.pdf.

10. Community E: Regulation (EC) no $1107 / 2009$ of the European Parliament and of the Council of 21 October 2009 concerning the placing of plant protection products on the market and repealing council directives 79/ 117/EEC and 91/414/EEC (91/414/EEC). Off J Europ Commun 2009, 52:1-50.

11. Klecka GM, Muir DCG, Dohmen P, Eisenreich S, Gobas FAPC, Jones KC, Mackay D, Tarazona JV, Van Wijk D: Introduction to special series: sciencebased guidance and framework for the evaluation and identification of PBTs and POPs. Integr Environ Assess Manag 2009, 5:535-538.

12. Brock TCM, Arts GHP, Maltby L, van den Brink PJ: Aquatic risks of pesticides, ecological protection goals and common aims in EU legislation. Integr Environ Assess Manag 2006, 2:e20-e46.

13. Hommen U, Baveco JM, Galic JN, van den Brink PJ: Potential application of ecological models in the European environmental risk assessment of chemicals I: review of protection goals in EU directives and regulations. Integr Environ Assess Manag 2010, 6:325-337.

14. Bro-Rasmussen F, Calow P, Canton J, Chambers P, Fernandes A, Hoffmann L, Jouany J, Klein W, Persoone G, Scoullos M, Tarazona JV, Vighi M: EEC water quality objectives for chemicals dangerous to aquatic organisms (list I). Rev Environ Contam Toxicol 1994, 137:83-110.

15. European Community: Regulation (EC) no 1907/2006 of the European Parliament and of the Council of 18 December 2006 concerning the Registration, Evaluation, Authorisation and Restriction of Chemicals (REACH), establishing a European Chemicals Agency, amending directive 1999/45/EC and repealing council regulation (EEC) no 793/93 and commission regulation (EC) no $1488 / 94$ as well as council directive $76 /$ 769/EEC and commission directives 91/155/EEC, 93/67/EEC, 93/105/EC and 2000/21/EC. Off J Europ Commun 2006. L 396/1.

16. European Community: Directive 98/8/EC of the European Parliament and of the Council of 16 February concerning the placing of biocidal products on the market. Off J Europ Commun 1998. L 123/1.

17. European Community: Directive 2000/60/EC of the European Parliament and of the Council of 23 October 2000 establishing a framework for community action in the field of water policy. Off J Europ Commun 2000. L 327/1.

18. European Community: Directive 2008/56/EC of the European Parliament and of the Council of 17 June 2008 establishing a framework for community action in the field of marine environmental policy (Marine Strategy Framework Directive). Off J Europ Commun 2008. L 164/19.

19. Macedo-Sousa JA, Soares AM, Tarazona JV: A conceptual model for assessing risks in a Mediterranean Natura 2000 Network site. Sci Tot Environ 2009, 2009(407):1224-1231.

20. Nienstedt KM, Brock TC, van Wensem J, Montforts M, Hart A, Aagaard A, Alix A, Boesten J, Bopp SK, Brown C, Capri E, Forbes V, Köpp H, Liess M, Luttik R, Maltby L, Sousa JP, StreissI F, Hardy AR: Development of a framework based on an ecosystem services approach for deriving specific protection goals for environmental risk assessment of pesticides. Sci Tot Environ 2012, 415:31-38.

21. EFSA: Scientific opinion on the development of specific protection goal options for environmental risk assessment of pesticides, in particular in relation to the revision of the guidance documents on aquatic and terrestrial ecotoxicology (SANCO/3268/2001 and SANCO/10329/2002). EFSA Journal 2010, 8(10):1821.

22. Nichols JW, Bonnell M, Dimitrov SD, Escher BI, Han X, Kramer MI: Bioaccumulation assessment using predictive approaches. Integr Environ Assess Manag 2009, 5:577-597.

23. Kelly BC, Ikonomou MG, Blair JD, Morin AE, Gobas FAPC: Food web-specific biomagnification of persistent organic pollutants. Science 2007, 317:236-238.

24. Weisbrod A, Woodburn K, Koelmans B, McElroy A, Parkerton T, Borgå K: Evaluation of bioaccumulation using in vivo laboratory and field studies. Integr Environ Assess Manag 2009, 5:598-623.

25. Kaneko H: Pyrethroid chemistry and metabolism. In Handbook of Pesticide Toxicology. 3rd edition. Edited by Krieger Rl, Doull J, Van Hemmen JJ, Hodgson E, Maibach HI, Ritter L, Ross J, Slikker W. Burlington: Elsevier; 2010:1635-1663.

26. Racke KD: Environmental fate of chlorpyrifos. Rev Environ Contam Toxicol 1993, 131:1-151.

27. Racke KD, Skidmore MW, Hamilton DJ, Unsworth JB, Miyamoto J, Cohen SZ: Pesticide fate in tropical soils. Pure Appl Chem 1997, 69:1349-1371.

28. Solomon KR, Bowhey CS, Liber K, Stephenson GR: Persistence of hexazinone (Velpar), triclopyr (Garlon) and 2,4-D in a northern Ontario aquatic environment. J Agric Food Chem 1988, 36:1314-1318.

29. European Community: Council directive of 15 July 1991 concerning the placing of plant protection products on the market (91/414/EEC). Off J Europ Commun 1991, 230(19.8):1-194

30. Klimisch $\mathrm{H}-\mathrm{J}$, Andreae M, Tillmann U: A systematic approach for evaluating the quality of experimental toxicological and ecotoxicological data. Reg Toxicol Pharmacol 1997, 25:1-5.

31. Breton RL, Gilron G, Thompson R, Rodney S, Teed S: A new quality assurance system for the evaluation of ecotoxicity studies submitted under the new substances notification regulations in Canada. Integr Environ Assess Manag 2009, 5:127-137.

32. McCarty $L S$, Borgert $C J$, Mihaich EM: Information quality in regulatory decision-making: peer review versus good laboratory practice. Environ Health Perspect 2012, 120:927-934

33. Siloxane D5 Board of Review: Report of the Board of Review for Decamethylcyclopentasiloxane (D5). Ottawa: Environment Canada; 2011:83. 
http://www.ec.gc.ca/lcpe-cepa/6E52AE02-5E01-48B0-86DE-0C366ACC863F/ CdR-BoR-D5_eng.pdf.

34. Boethling R, Fenner K, Howard P, Klecka G, Madsen T, Snape JR, Whelan MJ: Evaluating environmental persistence of organic pollutants: guidance for development and review of POP risk profiles. Integr Environ Assess Manag 2009, 5:539-556

35. Beyer A, Matthies M: Criteria for Atmospheric Long-range Transport Potential and Persistence of Pesticides and Industrial Chemicals. UBA-report 7/02. Berlin: Erich Schmidt-Verlag; 2002:260.

36. Matthies M, Klasmeier J, Beyer A, Ehling C: Assessing persistence and longrange transport potential of current-use pesticides. Environ Sci Technol 2009, 43:9223-9229.

37. Weed DL: Weight of evidence: a review of concepts and methods. Risk Anal 2005, 25:1545-1557.

38. Cook RB, Suter GW, Sain ER: Ecological risk assessment in a large river-reservoir: 1. Introduction and background. Environ Toxicol Chem 1999, 18:581-588.

39. Lowell RB, Culp JM: G DM: a weight-of-evidence approach for northern river risk assessment: integrating the effects of multiple stressors. Environ Toxicol Chem 2000, 19:1182-1190.

40. Burton GA, Batley G, Chapman PM, Forbes VE, Smith E, Reynoldson TB, Schlekat CE, van de Bentsen P, Bailer JA, Green AS, Dyer RL: A weight-ofevidence framework for assessing sediment (or other) contamination: improving certainty in the decision-making process. Human Ecol Risk Assess 2002, 8:1675-1698

41. Grapentine L, Anderson J, Boyd D, Burton GA, DeBarros C, Johnson G, Marvin C, Milani D, Painter S, Pascoe T, Reynoldson T, Richman R, Solomon $\mathrm{K}$, Chapman P: A decision-making framework for sediment assessment developed for the Great Lakes. Human Ecol Risk Assess 2002, 8:1641-1655.

42. Chapman PM: Determining when contamination is pollution - weight of evidence determinations for sediments and effluents. Environ Int 2007, 33:492-501

43. Rhomberg LR, Bailey LA, Goodman JE: Hypothesis-based weight of evidence: a tool for evaluating and communicating uncertainties and inconsistencies in the large body of evidence in proposing a carcinogenic mode of action - naphthalene as an example. Crit Rev Toxicol 2010, 40:671-696.

44. Borgert CJ, Mihaich EM, Ortego LS, Bentley KS, Holmes CM, Levine SL, Becker RA: Hypothesis-driven weight of evidence framework for evaluating data within the US EPA's Endocrine Disruptor Screening Program. Reg Toxicol Pharmacol 2011, 61:185-191.

45. Scheringer M, McLeod M, Matthies M, Klasmeier J, Witt J: Persistence Criteria in the REACH Legislation: Critical Evaluation and Recommendations. DessauRoßlau: German Federal Environment Agency; 2006:42. http://www.reachinfo.de/dokumente/gutachten_gesamtpersistenz.pdf.

46. OECD: Test No. 307: Aerobic and Anaerobic Transformation in Soil - Simulation Biodegradation Test, Guidelines for the Testing of Chemicals, Section 3. Paris: OECD; 2002:17. http://www.oecd-library.org/content/book/9789264070509-en.

47. OECD: Test No. 308: Aerobic and Anaerobic Transformation in Aquatic Sediment Systems - Simulation Biodegradation Test, Guidelines for the Testing of Chemicals, Section 3. Paris: OECD; 2002:19. http://www.oecd-library.org/ content/book/9789264070523-en.

48. OECD: Test No. 309: Aerobic Mineralisation in Surface Water - Simulation Biodegradation Test, Guidelines for the Testing of Chemicals, Section 3. Paris: OECD; 2004:21. http://www.oecd-library.org/content/book/9789264070547-en.

49. Lynch MR (Ed): Procedures for Assessing the Environmental Fate and Ecotoxicology of Pesticides. Brussels: SETAC Europe; 1995.

50. Series 835 - Fate, Transport and Transformation Test Guidelines. http:// www.epa.gov/ocspp/pubs/frs/publications/Test_Guidelines/series835.htm.

51. BBA: Richtlinien für die Prüfung von Pflanzenschutzmitteln im Zulassungsverfahren. Teil N, 4-1: Verbleib von Pflanzenschutzmitteln im Boden: Abbau, Umwandlung und Metabolismus. Braunschweig: Biologische Bundesanstalt für Land- und Forstwirtschaft: 1986:40.

52. BBA: Richtlinien für die Prüfung von Pflanzenschutzmitteln im Zulassungsverfahren. Teil IV, 5-1: Abbaubarkeit und Verbleib von Pflanzenschutzmitteln im Wasser/Sediment-System. Braunschweig, Germany: Biologische Bundesanstalt für Land- und Forstwirtschaft; 1990:55.

53. Nowak K, Miltner A, Gehre M, Schäffer A, Kästner M: Formation and fate of bound residues from microbial biomass during 2,4-D degradation in soil. Environ Sci Technol 2011, 45:999-1006

54. Dec J, Haider K, Schäffer A, Fernandes E, Bollag J-M: Use of a silylation procedure and ${ }^{13} \mathrm{C}$-NMR spectroscopy to characterize bound and sequestered residues of cyprodinil in soil. Environ Sci Technol 1997, 31:2991-2997.

55. Jablonowski ND, Koppchen S, Hofmann D, Schaffer A, Burauel P. Persistence of ${ }^{14} \mathrm{C}$-labeled atrazine and its residues in a field lysimeter soil after 22 years. Environ Pollut 2009, 157:2126-2131.

56. CEN: Soil Quality: Requirements and Guidance for the Selection and Application of Methods for the Assessment of Bioavailability of Contaminants in Soil and Soil Materials (ISO 17402:2008). Brussels: European Committee for Standardization; 2011:41.

57. NAFTA: NAFTA Guidance Document for Conducting Terrestrial Field Dissipation Studies, Regulatory Directive DIR2006-01. Washington, DC: US Environmental Protection Agency; 2006:55. http://www.epa.gov/oppefed1/ecorisk_ders/ terrestrial_field_dissipation.htm.

58. USEPA: Fate, Transport and Transformation Test Guidelines. OPPTS 835.6100 Terrestrial Field Dissipation. Washington, DC: United States Environmental Protection Agency, Prevention, Pesticides and Toxic Substances; 2008:50. http://nepis.epa.gov/Exe/ZyPDF.cgi?Dockey=P1003CMB.PDF.

59. FOCUS: FOCUS Groundwater Scenarios in the EU Review of Active Substances. Brussels: European Commission; 2000:122. http://www.ime.fraunhofer.de/ content/dam/ime/de/documents/AOe/FOCUS_2000_GW_Report_Main.pdf.

60. FOCUS: Guidance Document on Estimating Persistence and Degradation Kinetics from Environmental Fate Studies on Pesticides in EU Registration. Report of the FOCUS Working Group on Degradation Kinetics. Brussels: European Commission; 2006:434. http://focus.jrc.ec.europa.eu/dk/docs/ finalreportFOCDegKin04June06linked.pdf.

61. FOCUS: Assessing Potential for Movement of Active Substances and their Metabolites to Ground Water in the EU. Brussels: European Commission; 2009:604. http://www.ime.fraunhofer.de/content/dam/ime/de/documents/ AOe/FOCUS\%202009_FinalreportGW.pdf.

62. EFSA: Guidance for evaluating laboratory and field dissipation studies to obtain DegT50 values of plant protection products in soil. EFSA Journal 2010, 8(1936):1-67.

63. Matthies M, Witt J, Klasmeier J: Determination of soil biodegradation halflives from simulation test under aerobic laboratory conditions - a mechanistic model approach. Environ Pollut 2008, 156:99-105.

64. Loos M, Kraus M, Fenner K: Pesticide non-extractable residue formation in soil - insights from inverse modeling of degradation time series. Environ Sci Technol 2012, 46:9830-9837.

65. Klasmeier J, Brauer K, Matthies M: Critical evaluation of degradation kinetics of pesticides in water-sediment standard tests. In SETAC-Europe Annual Meeting. Porto: SETAC; 2007:18.

66. FAO: Revised Guidelines on Environmental Criteria for the Registration of Pesticides. Rome: Food and Agriculture Organization of the United Nations: 1989:51. http://www.fao.org/ag/AGP/AGPP/Pesticid/Code/Download/ ENVICRI.pdf.

67. OECD: Test No. 316: Phototransformation of Chemicals in Water - Direct Photolysis. Paris: OECD; 2006:53. http://www.oecd-ilibrary.org/environment/ test-no-316-phototransformation-of-chemicals-in-water-directphotolysis 9789264067585-en.

68. USEPA: Fate, Transport and Transformation Test Guidelines. OPPTS 835.2240 Photodegradation in Water. Washington, DC: United States Environmenta Protection Agency, Prevention, Pesticides and Toxic Substances; 2008:6. http://nepis.epa.gov/Adobe/PDF/P1005IXW.PDF.

69. JMAFF: The Guidelines Related to the Study Reports for the Registration Application of Pesticide. Appendix to Director General Notification. Tokyo: Ministry of Agriculture, Forestry and Fisheries of Japan; 2000:120. http:// www.mhlw.go.jp/english/topics/foodsafety/residue/dl/01.pdf.

70. EFSA: Opinion on a request from EFSA related to the default $\mathrm{Q}_{10}$ value used to describe the temperature effect on transformation rates of pesticides in soil. Scientific opinion of the Panel on Plant Protection Products and their Residues (PPR-Panel). (question no EFSA-Q-2007-048). Adopted on 12 December 2007. EFSA Journal 2007, 622:1-32.

71. FOCUS: Soil persistence models and EU registration. Brussels: European Commission, Health \& Consumer Protection Directorate-General; 1997. http://ec.europa.eu/food/plant/protection/evaluation/guidance/soil_en.pdf.

72. OECD: Test No. 305: Bioaccumulation in Fish: Aqueous and Dietary Exposure. Paris: OECD; 2012:72. http://www.oecd-ilibrary.org/content/book/ 9789264185296-en

73. Bacci E, Calamari D, Gaggi C, Vighi M: Bioconcentration of organic chemical vapors in plant leaves: experimental measurements and correlation. Environ Sci Technol 1990, 24:885-889. 
74. Trapp S, Matthies M, Scheunert I, Topp EM: Modelling the bioconcentration of organic chemicals in plants. Environ Sci Technol 1990, 24:1246-1252

75. Bizzotto EC, Villa S, Vighi M: POP bioaccumulation in macroinvertebrates of Alpine freshwater systems. Environ Pollut 2009, 157:3192-3198.

76. Gobas FA, De Wolf W, Burkhard LP, Verbruggen E, Plotzke K: Revisiting bioaccumulation criteria for POPs and PBT assessments. Integr Environ Assess Manag 2009, 5:624-637.

77. Borgå K, Kidd KA, Muir DC, Berglund O, Conder JM, Gobas FA, Kucklick J, Malm O, Powell DE: Trophic magnification factors: considerations of ecology, ecosystems, and study design. Integr Environ Assess Manag 2012, 8:64-84.

78. Conder JM, Gobas FA, Borga K, Muir DC, Powell DE: Use of trophic magnification factors and related measures to characterize bioaccumulation potential of chemicals. Integr Environ Assess Manag 2012, 8:85-97.

79. Tomy GT, Pleskach K, Ferguson SH, Hare J, Stern G, Maclnnis G, Marvin CH, Loseto L: Trophodynamics of some PFCs and BFRs in a Western Canadian Arctic marine food web. Environ Sci Technol 2009, 43:4076-4081.

80. OECD: Test No. 315: Bioaccumulation in Sediment-Dwelling Benthic Oligochaetes. Paris: OECD; 2008:33. http://www.oecd-ilibrary.org/ environment/test-no-315-bioaccumulation-in-sediment-dwelling-benthicoligochaetes 9789264067516-en.

81. Van Geest JL, Poirier DG, Sibley PK, Solomon KR: Measuring bioaccumulation of contaminants from field-collected sediment in freshwater organisms: a critical review of laboratory methods. Environ Toxicol Chem 2010, 29:2391-2401.

82. ECHA: Guidance on Information Requirements and Chemical Safety Assessment. Chapter R.11: PBT Assessment. European Chemicals Agency; 2008:97. http://echa.europa.eu/documents/10162/13632/ information_requirements_r11_en.pdf.

83. USEPA: EPI Suite 4.10. http://www.epa.gov/oppt/exposure/pubs/episuitedl. htm.

84. Lombardo A, Roncaglioni A, Boriani E, Milan C, Benfenati E: Assessment and validation of the CAESAR predictive model for bioconcentration factor (BCF) in fish. Chemistry Central Journal 2010, 4(Suppl 1):S1.

85. Zhao C, Boriani E, Chana A, Roncaglioni A, Benfenati E: A new hybrid QSAR model for predicting bioconcentration factor (BCF). Chemosphere 2008, 73:1701-1707

86. Arnot JA, Gobas FAPC: A review of bioconcentration factor (BCF) and bioaccumulation factor (BAF) assessment for organic chemicals in aquatic organisms. Environ Rev 2006, 14:257-297.

87. Tatarazako N, Oda S: The water flea Daphnia magna (Crustacea, Cladocera) as a test species for screening and evaluation of chemicals with endocrine disrupting effects on crustaceans. Ecotoxicol 2007, 16:197-203.

88. Ankley GT, Jensen KM, Kahl MD, Korte JJ, Makynen EA: Description and evaluation of a short-term reproduction test with the fathead minnow (Pimephales promelas). Environ Toxicol Chem 2001, 20:1276-1290.

89. Hutchinson TH, Ankley GT, Segner H, Tyler CR: Screening and testing for endocrine disruption in fish - biomarkers as "signposts", not "traffic lights", in risk assessment. Environ Health Perspect 2006, 114:4106-4014.

90. Segner H, Caroll K, Fenske M, Janssen CR, Maack G, Pascoe D, Schafers C, Vandenbergh GF, Watts M, Wenzel A: Identification of endocrinedisrupting effects in aquatic vertebrates and invertebrates: report from the European IDEA project. Ecotoxicol Environ Safety 2003, 54:302-314.

91. OECD: Test No. 216: Soil Microorganisms: Nitrogen Transformation Test Guidelines for the Testing of Chemicals, Section 2. Paris: OECD; 2000:10. http:// www.oecd-ilibrary.org/content/book/9789264070226-en.

92. OECD: Test No. 220: Enchytraeid Reproduction Test, Guidelines for the Testing of Chemicals, Section 2. Paris: OECD; 2004:22. http://www.oecd-ilibrary.org/ content/book/9789264070301-en

93. OECD: Test No. 222: Earthworm Reproduction Test (Eisenia fetida/Eisenia andrei), Guidelines for the Testing of Chemicals, Section 2. Paris: OECD; 2004:18. http://www.oecd-ilibrary.org/content/book/9789264070325-en.

94. European Commission: Technical Guidance Document on Risk Assessment in Support of Commission Directive 93/67/EEC on Risk Assessment for New Notified Substances Part II. Luxembourg: European Commission Joint Research Centre; 2003:337. http://ihcp.jrc.ec.europa.eu/our_activities/publichealth/risk_assessment_of_Biocides/doc/tgd/tgdpart2_2ed.pdf.

95. Posthuma L, Suter GW, Traas T (Eds): Species Sensitivity Distributions in Risk Assessment. Boca Raton: CRC Press; 2002
96. EFSA: Opinion of the scientific panel on Plant health, Plant Protection Products and their Residues on a request from EFSA related to the assessment of the acute and chronic risk to aquatic organisms with regard to the possibility of lowering the uncertainty factor if additional species were tested. (question no. EFSA-Q-2005-042). Adopted on 14 December 2005. EFSA Journal 2005, 301:1-45.

97. European Community: Council Directive of 15 July 1991 Concerning the Placing of Plant Protection Products on the Market (91/414/EEC). Brussels; 1991:449. http://eur-lex.europa.eu/LexUriServ/LexUriServ.do? uri=CONSLEG:1991L0414:20110601:EN:PDF.

98. Metcalf RL, Sanga GK, Kapoor IP: Model ecosystems for the evaluation of pesticide biodegradability and ecological magnification. Environ Sci Technol 1971, 5:709-713.

doi:10.1186/2190-4715-25-10

Cite this article as: Solomon et al:: Assessment of PBTs in the European Union: a critical assessment of the proposed evaluation scheme with reference to plant protection products. Environmental Sciences Europe $201325: 10$

\section{Submit your manuscript to a SpringerOpen ${ }^{\odot}$ journal and benefit from:}

- Convenient online submission

- Rigorous peer review

- Immediate publication on acceptance

- Open access: articles freely available online

- High visibility within the field

- Retaining the copyright to your article

Submit your next manuscript at $>$ springeropen.com 